\title{
Taking care in prehistoric Latin America: A case study of care giving among hunter-gatherers in the Final Late Holocene
}

\section{Terri Fisher}

\begin{abstract}
A published case of metastatic cancer from a hunter-gather group in pre-Columbian Argentina analysed the effects this illness would have on group dynamics. This essay uses the published details of the case study to analyse the possibility of care being provided to the dying individual. After a detailed discussion on the skeletal analysis and diagnosis offered by the original authors, this essay proposes that prior to his illness this individual would have been an active contributor to his group, likely involved in the transport and manipulation of stone. The functional impact the individual would have experienced as the result of his illness is discussed including the impact on the rest of his group, i.e. reduced contributions to group subsistence and inability to maintain residential mobility in a nomadic lifestyle. This essay argues that, based on the accommodation of their ill member by continuing to supply food despite his deteriorating state, this group of hunter-gatherers valued their individual members more so than their contribution to the group. This case study provides an insight into the value system of a pre-Columbian hunter-gatherer group outside of the more commonly examined subsistence activities, trading and burial practices.
\end{abstract}

\section{Keywords}

pre-Columbian Argentina, bioarchaeology of care, skeletal analysis, hunter-gatherers 


\section{Introduction}

Luna et al.'s 2008 paper, entitled 'A case of multiple metastasis in Late Holocene hunter-gatherers from the Argentine Pampean region', analysed the impacts individual illness may have had on group dynamics. Yet, the immediate response-specifically, the prospect of interpreting if care would have been provided to the individual — was not considered in the original publication. This was justified by reference to Dettwyler's (1991) well-known publication opposing the interpretation of care in paleopathology. However, this view has since been rebutted by Tilley (2015) opening up the potential to interpret the provision of care in prehistoric times. Seeing as Luna et al. (2008) published prior to Tilley's (2015) rebuttal, it is worth investigating a potential interpretation of the life of that individual while ill. This is important because Luna et al.'s 2008 paper provided an interpretation of the broader concepts of group dynamics even though their analysis was based on a single skeleton case. Establishing if these remains can provide insights into how the group responded to the illness before attempting to theorise how the illness affected group dynamics is an important aspect to consider for the bioarchaeological analysis of this individual. After all, how the group responded to an ill member is a significant factor affecting group dynamics.

In an effort to elaborate on the analysis of these remains, this essay will present an interpretation of the experiences this individual would have endured during the course of his illness. Using a variation on the four stages of Tilley's (2012) 'The bioarchaeology of care' model, this analysis will begin by placing the individual within the context of hunter-gatherer lifestyle in the region. Secondly, the diagnosis provided by Luna et al. (2008) will be expanded on in order to establish the progression of the individual's illness. Finally, a determination of the functional impact of the individual's condition on their daily life will be attempted. Based on this prognosis, and the relevant lifestyle factors, this essay will propose a reconstruction of the immediate response to the illness, including the types of care this individual may have received. Finally, an interpretation of the social and cultural implications of this response will be proposed with reference to the already established social and cultural context of hunter-gatherer groups in the region. 


\section{Context}

The Pampean grasslands covers southern parts of Brazil, all of Uruguay and a large amount of Argentina. Most of that area shares the same flora and fauna with some regional variations, and high winds affect most of the area (Politis 2008; Flensborg 2011). The grassland is intersected by small forested areas located near water sources. Significant evidence of hunter-gatherers has been found throughout the regions including in the isolated hilly regions (Politis 2008). The individual under discussion was excavated at a cemetery called Chenque 1 . Chenque 1 is located in a hilly semi-arid area within Lihue Calel National Park (Flensborg et al. 2015). Cemetery sites such as this one provide some of the strongest insights into the hunter-gatherer lifestyles in the area.

Increasing complexity of burials in the Late Holocene has been seen as indicative of significant socioeconomic changes in the region's hunter-gatherer groups (Martínez et al. 2012). The repeated use of the same sites for burial, along with the more frequent use of secondary burials and inclusions of grave goods, show an increased investment in the dead (Martínez et al. 2012). This change is considered to be the result of 'major changes and reorganisation of cultural systems towards the Final Late-Holocene', ca. 950-1700 CE (Flensborg et al. 2015:816). The aspects of daily life potentially affected by these changes are varied; however, several are likely to have been significant in this case: changes to territoriality, increased resource exploitation and increased social interaction and networking (Politis 2008; Flensborg 2011; Martínez et al. 2012; Flensborg et al. 2015).

The changes to territoriality seem to be signified by a reduction in residential mobility and an increase in networking, including possible trade (Politis 2008). The proposed reduction in residential mobility is consistent with the grave goods found at Chenque 1. Items found were made from raw materials sourced at a great distance: from the Atlantic coast, the trans-Andean region and multiple other areas - the combination of which results in a travel radius of at least 150 kilometres (Luna et al. 2008; Politis 2008; Beron et al. 2009). As this range of group mobility is unlikely, it supports the idea that the circulation of 'exotic material with highly symbolic value' (Politis 2008:254) is evidence of trade between different hunter-gatherer groups inhabiting various areas in the region as opposed to evidence of extended mobility (Beron et al. 2009). 
This capacity to access resources from outside a likely mobility range is also present in research conducted into subsistence practices. Isotopic analysis shows that those buried at Chenque 1 had a continental and marine diet (Luna et al. 2008; Flensborg 2011), despite the distance between the cemetery and the ocean. The presence of marine mollusc remains at archaeological sites throughout the Pampean region would seem to support those results, although Bonomo and Aguirre (2009) question whether these were used as a food source. The Late Holocene changes in resource exploitation are also apparent in the beginnings of horticulture (Politis 2008). This is evidenced by the use of grinding stones (Politis 2008), and the increasing prevalence of caries found in Late Holocene skeletal remains (Flensborg 2011). Flensborg's (2011) analysis of dento-alveolar lesions present in dentition from the region attributed this increase to the rising use of plants as a food source.

Of course, hunting activities of the hunter-gatherer lifestyle is also an important aspect of subsistence. The primary prey of the Pampean hunter-gatherers was the guanaco, a camelid species resembling a llama (Flensborg 2011). It was supplemented by local deer and the rhea, a large flightless bird similar to an emu (Flensborg 2011; Salemme and Frontini 2011). The hunting techniques used to catch these animals are unknown, although a weapon made from two stones attached to each end of some kind of cord, called a bola, was likely used (Politis 2008). These animals are all capable of speeds faster than that of Homo sapiens. Therefore, hunting could presumably have involved tracking, running and throwing. Smaller mammals were also used as food sources (Flensborg 2001); however, traps may have been more effective at gathering these animals.

The final aspect of hunter-gatherer life in the Final Late Holocene that may be relevant is the advent of craftsmanship (Politis 2008; Flensborg 2011). This adaption may have been related to the use of horticulture as subsistence. The standardisation of the design of grinding stones (Flensborg 2011) is an indication of a rise in craftsmanship. Pottery became relatively complex in this period with the development of decorative techniques such as painting and incision; pottery handles and engraved plates are also found (Politis 2008), which indicate a diversity of potential uses. Lithic technology advanced as well, leading to the construction of stone monuments (Politis 2008). 


\section{The burial}

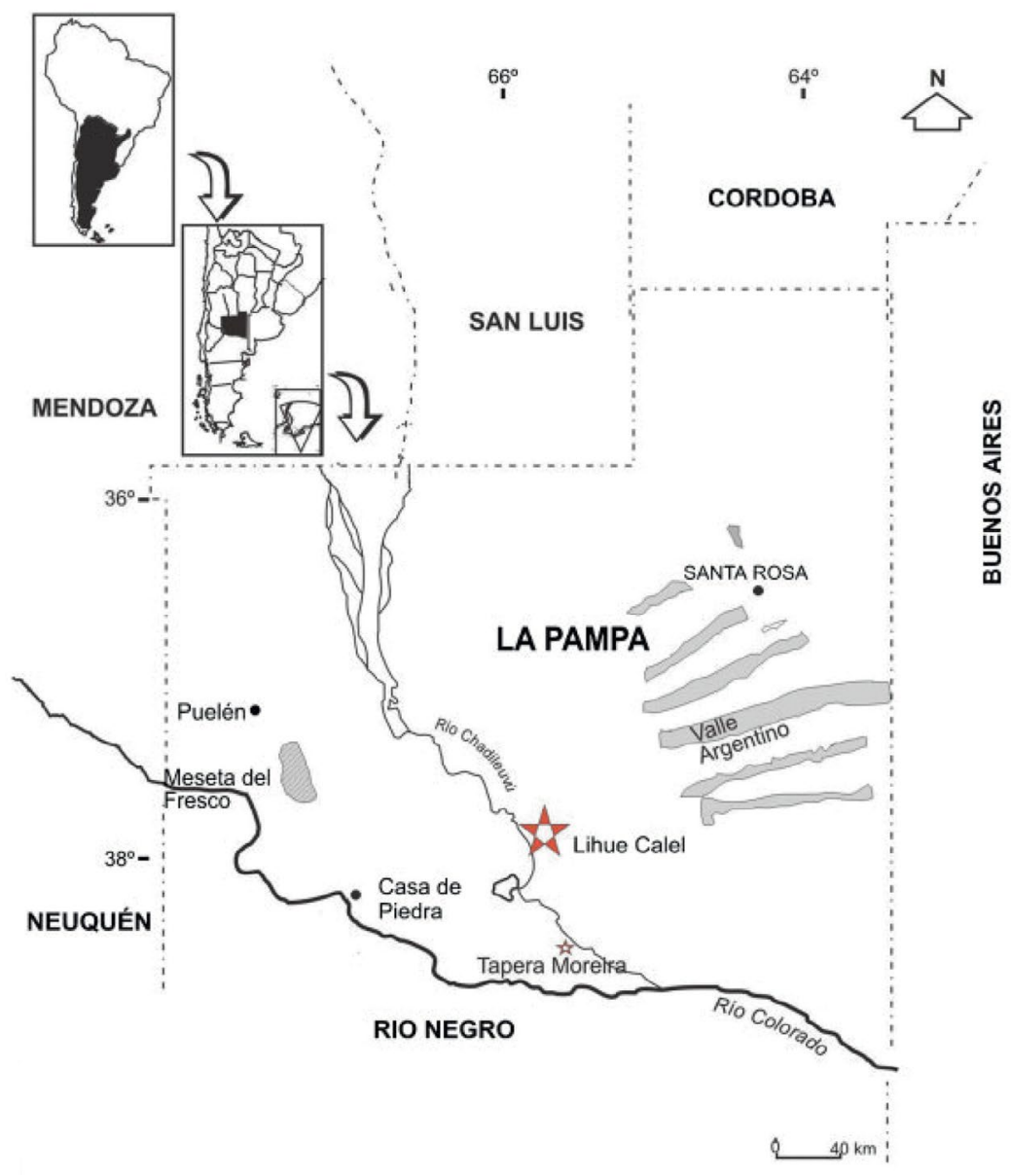

Figure 1: Location of the Lihue Calel National Park, and the Chenque 1 site Source: Luna et al. 2008:493 (Licence no. 4032330886796), reproduced with permission.

Chenque 1 is a prehistoric cemetery site located in the Lihue Calel National Park in the La Pampa province. This is in the Western part of the much larger Pampean Region located mainly in Argentina (Luna et al. 2008; Figure 1). Chenque 1 was in use in the Final Late Holocene 920-1580 CE. The people using this cemetery were hunter-gatherers, and it is theorised that 
multiple groups used this one cemetery (Luna et al. 2008). The cemetery itself is a complex elliptical stone structure with at least two levels of burials (Politis 2008). The upper level is above 30 centimetres and had a minimum number of individuals (MNI) of 53. The lower level had an MNI of 158, including adults, subadults, males and females (Luna et al. 2008). The site had multiple types of burials: primary, secondary and dispositional —in which the anatomical structure of the body is intentionally altered prior to the initial burial (Politis 2008).

The individual in question was found in Burial 12 in the lower level of Chenque 1. The skeleton is that of an adult male aged approximately 40-50 years old at death. He was buried in flexed position at the southwest end of the site (Luna et al. 2008). Luna et al. (2008) noted that two valve beads were associated with Burial 12 however no information was provided regarding whether this was a high or low number of grave goods in the context of this cemetery or this region.

\section{Skeletal analysis}

The skeletal remains of Burial 12 were approximately 70 per cent complete. The authors suggested multiple unspecified taphonomic agents may be the cause of most of the missing bones, although the skull may have been deliberately separated from the body at burial. The cemetery contained several examples of skulls buried in isolation (Luna et al. 2008). Burial 12's remains were missing the cranium, teeth (except for the first right lower premolar), and sternum; the left scapula, clavicle, radius and ulna; the right humerus, patella and tibia, and most of both hands (Luna et al. 2008:494). Burial 12's remains also presented a set of lesions that were spread across the thorax (dorsal arches of vertebrae and diaphyses of ribs), pelvis (os coxae and sacrum), scapula (body and coracoid process), proximal epiphyses of both femora, left humerus and the right ulna (Luna et al. 2008:495). For more information on the remains themselves please see Luna et al.'s (2008) original article, which contains multiple images including those showing the spread and details of the lesions.

Luna et al. (2008) primarily addressed the lesions on the skeleton, but also analysed some exostoses at muscle and ligament attachment sites, which provided some insight into the pre-illness life of this man. The authors 
interpreted repeated strong use of muscles in the neck, pectoral girdle and trunk based on the analysis of multiple exostoses formed at the relevant muscle attachment sites (Mariotti et al. 2007; Luna et al. 2008:498).

In their discussion of the impact a terminal disease might have had on group dynamics, Luna et al. (2008) does not discuss Burial 12's activities prior to his illness. Of course, the lack of detail on this subject does not mean that a thorough skeletal analysis was not completed. As the original article did not discuss Burial 12's activity levels, it would have been superfluous to include additional data that may have resulted from such an analysis. The data that might have been pertinent is the presence or absence of wear on the skeleton, which might have given stronger indications of Burial 12's activities prior to his illness and thus how the loss of his ability to complete these activities may have affected the rest of the group. It is noted that the bones exhibiting lesions were highly fragmented. This is not unexpected as the lesions weaken these bones, making them susceptible to fracture prior to death (Ortner 2003; Aufderheide and Rodríguez-Martin 2011), therefore they would be among the most likely to suffer damage postmortem. The results of analysis on potential antimortem fractures may also have provided an indication of Burial 12's level of activity prior to his death. While it is certainly possible that none of these indicators were present in this instance, Luna et al. (2008) did not include any indication that these aspects were considered when interpreting the impacts of Burial 12's condition. This is unfortunate, as the lack of data on this point leaves a gap in both my own analysis and that provided by Luna et al. (2008).

\section{Diagnosis}

The diagnosis proposed by Luna et al. (2008) is neoplasia that caused secondary manifestations, otherwise known as multiple metastasis or metastases carcinoma (Aufderheide and Rodríguez-Martin 2011). Luna et al. (2008) did provide a differential diagnosis, looking at leukemia and multiple myeloma as possible alternatives, although both were ruled out based on the type and location of the lesions. It is noted that multiple metastasis is a rare diagnosis in paleopathology; however, the diagnosis is reasonable based on the information provided.

It is not possible to determine if the cancer was the cause of death. Although it can be said that, if the cancer was not the cause of death, it would have been fatal if the course of the illness was not interrupted. Multiple metastasis is 
known to be the most common type of cancer that affects the skeleton (Ortner 2003). However, it is not a specific cancer diagnosis. The term multiple metastasis refers to cancer that has spread from one tumour in a specific part of the body to form malignant tumours in multiple areas of the body. In their article, Luna et al. (2008) look at the two most common types of cancer to develop into multiple metastasis-prostate and breast cancer-and ruled out both forms, stating that both prostate and breast cancer result in osteoblastic lesions, which is not consistent with Burial 12. This is not always the case as these conditions can produce either osteolytic or osteoblastic lesions (Ortner 2003; Aufderheide and Rodríguez-Martin 2011). So, while breast cancer is unlikely due to the sex of Burial 12, prostate cancer is still a possibility. Although, as Luna et al. (2008) had access to the remains and were therefore in the best position to analyse the lesions, their dismissal of prostate cancer as a diagnosis is not opposed here. Osteolytic lesions are also indicative of lung, thyroid, kidney or gastrointestinal cancer (Ortner 2003; Luna et al. 2008; Aufderheide and Rodríguez-Martin 2011). This author agrees with Luna et al.'s (2008) conclusion that it is not possible to determine which of the above forms of cancer this individual suffered based on the skeletal evidence.

Osteolytic lesions indicate a slowly progressing illness (Ortner 2003; Aufderheide and Rodríguez-Martin 2011). This concurs with Luna et al.'s (2008) analysis, stating that the presence of both early and late stage lesion development indicates a long-term condition of at least several months. As the initial type of cancer cannot be determined, it is not possible to be exact regarding the symptoms this man would have endured during his final months. Nevertheless, there are some general symptoms that nearly all cancer sufferers experience. Research on modern terminally ill cancer patients shows that the three most constant and debilitating symptoms are pain, weakness and fatigue, with patients also likely to suffer the following symptoms to varying degrees: shortness of breath, anxiety, depression, lack of appetite, memory problems, vomiting, nausea, numbness/tingling, sleeping problems, restlessness, constipation and anorexia (Kwon et al. 2006; Ruijs et al. 2013; Jensen et al. 2014). While it is not possible to know which of these this man suffered, Kwon et al. (2006) found that modern patients had an average of $11 \pm 2.5$ symptoms, so it is likely he had most if not all of the above symptoms. Any combination of these symptoms would have had the obvious effects of reduced physical activity and eventual muscle atrophy. It is important to note, as Luna et al. (2008) did, that at no point is there any 
indication or precedent that this man would have experienced any reduction in cognitive capacity. He would have remained aware of his steadily reducing capabilities throughout his illness.

The research into modern patients has shown a significant increase in the severity of symptoms at an average of four months prior to death. A decline to being bedridden and unable to take care of intimate needs, i.e. toilet, feeding, etc., happen at an average of one month prior to death (Ruijs et al. 2013). This research was conducted in a modern Western medical environment, so it is likely that these patients received treatment that both extended their life and relieved their symptoms to a certain degree. As Burial 12 would not have received such medical aid, it is likely that he progressed through these stages more rapidly with minimal, if any, symptom relief.

\section{Functional impacts}

The functional impacts of this disease may seem self-evident. This illness progressed slowly, likely over at least several months; during which time the individual would have been forced by pain and fatigue to reduce his contribution to his group. It is not possible to be certain of his contribution levels prior to his illness. His involvement in any subsistence practices, particularly hunting, would have been affected to the point where he would not have been capable of participating. However, the assertion by Luna et al. (2008) that this man had a strong trunk, pectoral girdle and neck would indicate that whatever the exact nature of contributions, he regularly performed tasks that required him to be active and strong. As the development of exostoses at muscle attachments requires the build-up of impressive muscle mass (Mariotti et al. 2007), the indications of Burial 12's significant muscularity at the trunk, pectoral girdle and neck —all areas used during heavy lifting — show it is possible that he was involved in the movement and perhaps creation of the stone monuments.

However, pain, weakness and fatigue would have made such activity increasingly difficult, and ultimately impossible to continue as his disease progressed. Burial 12's capacity to travel would have been affected. The reduction in residential mobility of hunter-gatherer groups in the region is significant here as Burial 12's reduced travelling capacity would have had less impact on his group compared to earlier times. As he became more inactive, and as the lack of appetite and weight loss had their effect, his muscles would have begun to atrophy. Luna et al. (2008) considered the muscle atrophy to 
have had the strongest impact on Burial 12, perhaps because it was assumed his strength was his main contribution to the group. The atrophy would have been very visible to both himself and to those around him.

This is not to imply that this man was bedridden or incapable of looking after himself. His capacity would have slowly reduced over time, but it is unlikely he needed constant care until the very end of his life. It is highly possible that this man was capable of taking care of himself for most of the duration of his illness, albeit with increasing difficulty. It is also possible that he remained an active contributor to the group by performing tasks of which he was still capable until very shortly before his death. I will discuss this possibility in more detail in the proposed model of care.

\section{Interpretation of care}

Luna et al. (2008) discussed the functional impacts of Burial 12's conditionand indeed the types of assistance he would have needed during his illness - and yet refused to consider the possible treatment of Burial 12 by his group. This decision was based on Dettwyler's (1991) influential article opposing the interpretation of compassion in paleopathology. As Tilley (2015) pointed out, Dettwyler (1991) conflated the related but separate interpretations of the act of providing care and the motivations for those actions. If evidence indicates that action was taken to extend an individual's life or relieve their suffering, then the provision of care can be a valid interpretation. Although, Dettwyler's (1991) contention that the interpretation of compassion is unjustifiable has some merit. In cases where the provision of care can be reasonably interpreted, any claims that the motivations for, or the manner of, said care was compassionate are unverifiable. Although, this analysis questions whether the current emotional capabilities of our species are so very different from earlier peoples, i.e. it is equally invalid to assume that compassion was absent as it is to assume it was present. Regardless, this essay is not suggesting that Burial 12's treatment was born out of compassion. It is, however, suggesting that Luna et al.'s (2008) refusal to continue analysis beyond Burial 12 's required treatment, and refusal to consider if that treatment was provided, was somewhat shortsighted. 


\section{Model of care}

In 'The bioarchaeology of care', Tilley (2012) divides care into two main categories: direct support or accommodation. Direct support is defined as actual intervening actions to assist the individual such as nursing, medical intervention, etc.; whereas accommodation is the adjustment of activities in order to make provisions for the relevant individual (Tilley 2012). As discussed in the diagnosis, it is likely that Burial 12 only required direct support in his final days (Ruijs et al. 2013). His increasingly severe symptoms would have prevented him from contributing to the group in a physically demanding way. However, it is still likely that he was able to maintain his own hygiene, toilet, eating, etc. For the majority of his illness, Burial 12 probably only required 'accommodation' from his group. His group did not abandon him or refuse to allow him food once he became unable to perform his 'normal' activities. If that had been the case, he would have died well prior to the full spread of the lesions. Burial 12 may have remained a contributing member of the group by adapting to those activities he was still able to complete. This may have included food preparation, making traps or bolas, pottery, conducting trade, etc.; although the level of his continuing contribution to the group, if any, can never be verified. Regardless of Burial 12's level of contribution, his group does appear to have 'accommodated' his illness. This is evidenced by the provision of food during the course of his illness, and by Burial 12 remaining with his nomadic group in spite of his, and therefore the group's, reduced travelling capabilities.

Eventually the course of the disease would have made it impossible for Burial 12 to remain self-sufficient. Since research into timeframes relating to terminally ill cancer patients is conducted on those under modern medical care, it is not possible to determine the exact length of time Burial 12 required direct support prior to his death. Although, based on Ruijs et al. (2013), it was likely only a few weeks at most. At this stage, it is possible that the members of his group simply left him alone once he could not fend for himself. If the assumption of direct support is allowed, then Burial 12 would have needed assistance to toilet and to eat, and if the group was mobile at the time he would have needed to be transported. While there is no hard evidence supporting direct care, accommodation can be argued based on length of time Burial 12 survived as evidenced by the spread of the cancer over the skeleton, as well as long-term nature of the disease itself. 


\section{Interpretation}

The accommodation of Burial 12's deteriorating condition suggests a level of investment in the individuals of that group. Unfortunately, without comparative details it is not possible to situate this within the broader interpretations of increasing social and economic complexity. Nor is it possible to make any interpretations on how Burial 12 responded to his illness. He may have remained an active contributor of the group, or he may have retreated from any human interaction. Regardless of his response, he remained alive long enough for the disease to spread as far across his skeleton as this disease is able. As he would have been restricted from gathering his own subsistence, even while he was still capable of feeding himself, it is likely his group showed enough investment in his life that he was provided with food once he became incapable of gathering his own. Thus, this group of hunter-gatherers valued Burial 12's life above that of his 'normal' contribution to the group.

\section{Conclusion}

The case of Burial 12 is an interesting instance of terminal illness among Latin American hunter-gatherers. This individual lived within a hunter-gatherer society for a significant period while seriously ill. This gives researchers a direct insight into behaviour outside of hunting, farming, fishing, trading or interring. This insight is an intimate one: how they responded to their ill and dying members. It is apparent that this hunter-gatherer group did show adjustment to at least indirectly support an ailing member. The possibility that this was a new adaptation that was brought about by broader social and economic changes is interesting; although it would require further archaeological evidence and research to investigate.

Luna et al.'s (2008) conclusions were remarkably similar to this analysis considering their discussion refused to consider the illness from Burial 12's individual perspective, instead focusing on the inference of 'the consequences that this disease would have had on the dynamics of the group in which this person lived' (Luna et al. 2008:492). It must be noted that the lack of verifiable detail of Burial 12's life during the progression of his illness makes any suggestion of consequences for group dynamics to be highly questionable. Not knowing the level to which the residential mobility of the group was affected-or indeed their subsistence practices or trade capabilities or other unknown factors - any theory would be based on an unsupportable number of assumptions. 
While the case of Burial 12 is a good example of illness within a prehistoric cultural group, unfortunately this insight cannot be expanded to all groups in the region and therefore it does not significantly advance our general knowledge of these hunter-gather groups. It does, however, provide some insight, albeit small, into group values of a single hunter-gatherer society in prehistoric Latin America.

\section{Acknowledgements}

I would like to thank Dr Lorna Tilley and the anonymous reviewers for their comments on earlier drafts of this essay, and John Wiley \& Sons for their permission to reproduce Figure 1. I would also like to acknowledge, with gratitude, Luna et al. (2008) for publishing such an interesting case for our enrichment.

\section{References}

Aufderheide AC, Rodríguez-Martin C. 2011. The Cambridge encyclopaedia of human paleopathology. Cambridge (UK): Cambridge University Press.

Beron MA, Luna LH, Barberena, R. 2009. Isotopic archaeology in the Western Pampas (Argentina): Preliminary results and perspectives. Int J Osteoarchaeol. 19(2):250-265. doi.org/10.1002/oa.1049

Bonomo M, Aguirre ML. 2009. Holocene molluscs from archaeological sites of the Pampean region of Argentina: Approaches to past human uses. Geoarchaeology. 24(1):59-85. doi.org/10.1002/gea.20254

Dettwyler KA. 1991. Can paleopathology provide evidence for "compassion"? Am J Phys Anthropol. 84(4):375-384. doi.org/10.1002/ajpa.1330840402

Flensborg G. 2011. Dento-alveolar lesions and palaeodietary inferences from the Paso Alsina 1 site (Eastern Pampean-Patagonian Transition, Argentina). J Comp Hum Biol. 62(5):335-350. doi.org/10.1016/j.jchb.2011.08.005

Flensborg G, Martínez G, Bayala PD. 2015. Mortality profiles of huntergatherer societies: A case study from the Eastern Pampa-Patagonia transition (Argentina) during the Final Late Holocene. Int J Osteoarchaeol. 25(6):816-826. doi.org/10.1002/oa.2348 
Jensen W, Bialy L, Ketels G, Baumann FT, Bokemeyer C, Oechsle K. 2014. Physical exercise and therapy in terminally ill cancer patients: A retrospective feasibility analysis. Support Care Cancer. 22(5):12611268. doi.org/10.1007/s00520-013-2080-4

Kwon YC, Yun YH, Lee KH, Son KY, Park SM, Chang YJ, Wang XS, Mendoza TR, Cleeland CS. 2006. Symptoms in the lives of terminal cancer patients: Which is the most important? Oncology. 71(1-2):69-76. doi.org/10.1159/000100450

Luna LH, Aranda CM, Bosio LA, Beron MA. 2008. A case of multiple metastasis in Late Holocene hunter-gatherers from the Argentine Pampean region. Int J Osteoarchaeol. 18(5):492-506. doi.org/10.1002/oa.950

Mariotti V, Facchini F, Belcastro MG. 2007. The study of entheses: Proposal of a standardised scoring method for twenty-three entheses of the postcranial skeleton. Coll Antropol. 31(1):291-313.

Martínez G, Flensborg G, Bayala P. 2012. Human corpse manipulation and the body as symbol: A case study from the Eastern Pampa-Patagonia transition (Argentina) during the Final Late Holocene. J Anthropol Archaeol. 31(2):215-226. doi.org/10.1016/j.jaa.2011.12.002

Ortner DJ. 2003. Identification of pathological conditions in human skeletal remains. 2nd ed. San Diego (CA): Academic Press.

Politis G. 2008. The Pampas and Campos of South America. In: H Silverman, WH Isbell, editors. Handbook of South American Archaeology. New York (NY): Springer. pp. 235-260. doi.org/10.1007/978-0-387-74907-5_14

Ruijs CDM, Kerkhof Ad JFM, van der Wal G, Onwuteaka-Philipsen BD. 2013. Symptoms, unbearability and the nature of suffering in terminal cancer patients dying at home: A prospective primary care study. BMC Fam Pract. 14(1):201-201. doi.org/10.1186/1471-2296-14-201

Salemme M, Frontini R. 2011. The exploitation of RHEIDAE in Pampa and Patagonia (Argentina) as recorded by chroniclers, naturalists and voyagers. J Anthropol Archaeol. 30(4):473-483. doi.org/10.1016/j.jaa. 2011.08.001

Tilley L. 2012. The bioarchaeology of care. SAA Archaeol Rec. 12(3):1-6.

Tilley L. 2015. Theory and practice in the bioarchaeology of care. New York (NY): Springer. doi.org/10.1007/978-3-319-18860-7 
This text is taken from the The Human Voyage: Undergraduate Research in Biological Anthropology: Volume 1, 2017, edited by Alison Behie, published 2017 by ANU eView, The Australian National University, Canberra, Australia.

dx.doi.org/10.22459/HV.01.2017.02 